\title{
The IEEE Actionable Data Book: A Platform For Inclusive Education
}

\author{
Edilson Arenas \\ School of Engineering and \\ Technology \\ CQUniversity \\ Melbourne, Australia \\ e.arenas@cqu.edu.au
}

\author{
Tyde Richards \\ IEEE Actionable Data Book for \\ S.T.E.M. Education \\ IEEE LTSC \\ San Diego, USA \\ tyderichards@gmail.com
}

\author{
Avron Barr \\ IEEE Actionable Data Book for \\ S.T.E.M. Education \\ The LETSI Foundation \\ Aptos, USA \\ avron@aldo.com
}

\begin{abstract}
The phenomenal growth in the adoption of mobile cellular devices in the developing world has open the opportunity to develop a global platform for connected learning - a software and data infrastructure that will serve as the foundation for the many systems that we build to realize the idea of equal access to educational services. In this paper, we argue that the most challenging factor for the deployment of this platform is the development and implementation of an engineering standard specification grounded in new learning theories and principles. We propose the IEEE ADBook that has the potential to become the first truly global framework for connected earning supporting inclusive education in developing countries.
\end{abstract}

Keywords — interoperability; inclusive education;connected learning;learning standard; stem education

\section{INTRODUCTION}

In early September 2000, the United Nations Millennium Summit officially agreed upon eight international development goals to help citizens in the world's poorest countries improve living conditions by the year 2015 [1]. Two years from the deadline, significant progress has been achieved on a broad front. However, according to the latest statistics from the United Nations [1], government and community efforts must intensify if these goals are to be crystallised within this timeframe. In this regard, technology is seen as a key enabler, particularly in the context of inclusive education, giving all citizens of the world access to high quality education so that they may develop their full potential. The need is urgent: education is our greatest weapon against ignorance and poverty and the hatred and violence they generate.

Of particular attention is the dramatic rise in the adoption of mobile cellular devices in the developing world, which in turn has brought large numbers of people on-line. At the end of 2011, three out of four worldwide mobile cellular subscriptions were in the developing world with these subscriptions expected to grow yearly at double-digit rates in years to come [1].

This phenomenal growth in mobile telecommunications in the developing world provides a unique opportunity to the global humanitarian learning technology community. When students and teachers have access to globally available online resources, new pathways to learning open up, both in the classroom and for independent learners. To enable this vision, we propose to develop a global platform for connected learning - a software and data infrastructure that will serve as the foundation for the many systems that we build to realize the idea of equal access to educational services.

Acknowledging a wide range of entrenched political, economic, social and cultural challenges, there are specific institutional and technical issues that may directly affect the deployment of such a global learning platform in developing countries: the absence of teachers; lack of knowledge experts; limited community engagement; cost of development and integration; unwillingness to implement learning technologies; and unfamiliarity with the use of technology, amongst others. However, we argue that the most critical factor for the deployment of this platform for global connected learning is the development and implementation of an engineering specification such as those produced by the open and rigorous process in IEEE standards activities - a modern web software specification grounded in new learning theoretical frameworks and consistent with contemporary students' needs, preferences, beliefs, and perceptions.

In this paper, we address these issues in light of the IEEE LTSC (Learning Technology Standards Committee) overarching efforts to produce an educational platform: the IEEE Actionable Data Book (IEEE ADBook). This platform is aimed to catalyse the development of a global standard for connected learning, grounded in teaching and learning principles and built around global humanitarian ideals. The first technology demonstrator of this platform is planned to be a rich and interactive guidebook for the new UNESCO World Heritage Site on Bali, Indonesia. 


\section{RELATED WORK}

For the last two decades, the use of learning technologies in the developed world has transformed the educational landscape. Today, for example, virtually all universities have adopted a learning management system (LMS) to manage learning resources, communication, assessment, content creation and content delivery [2], [3].With the advent of new and related-emerging technologies such as tablets, mobile cellular devices, cloud-services and eBooks, this trend in education is expected to continue in all sectors. However, in terms of adoption of emerging technologies, the potential and need for change and innovation may be greater in the developing world compared to developed countries. According to the 2010 ITU technical report [4], in the developed world the mobile cellular market reached a plateau in 2010 compared to the explosive growth in adoption in developing countries where total mobile subscriptions increased to $73 \%$ at the end of 2010 . Given the quintessential role technology plays in the well-being of human kind, there has never been a better time to leverage such a phenomenal growth in technology adoption in the developing world, to contribute to solutions to the global problems articulated in United Nations Millennium Summit. In terms of education, a global platform for connected learning, such as the IEEE ADBook, would play a key role in the delivery of inclusive education to disadvantaged people. The future is bright but a series of institutional and technological barriers may hinder the development of this idea.

Taking the institutional perspective, educational technologies have been advocated to enhance the possibilities for conceptualising, designing, facilitating, monitoring and assessing student learning and educational activities [5]. In this respect, the institutional promise has been for a complete transformation of traditional ways of teaching and learning into environments where learners and teachers can actively and socially engage in the construction of more meaningful learning experiences [6], [7]. As stated, the uptake of learning technologies has been high, particularly through the use of LMSs. Despite significant investment in infrastructure and training, however, the promised transformative effect on student learning is yet to be achieved. Many institutions merely move towards digital and networked equivalents of the processes that have traditionally characterised teaching and learning: for example, the provision of digital instead of hardcopy print readings and course materials; online instead of hardcopy submission of assignments; and the supplementing of faceto-face communications with online exchanges. While these changes arguably contribute to a higher level of convenience and efficiency, in themselves they do not comprise a significant qualitative change in the processes of teaching and learning as has been anticipated by much of the rhetoric promising paradigmatic-level transformation.

Taking the technical perspective, a raft of studies have been conducted to investigate barriers to more significant change (e.g., [6], [7], [8], [9], [10]). Such studies suggest that technical barriers include teachers' reluctance to adopt online tools; the cost of the implementation of the systems; the dependency on vendors and manufacturers; the cost of training; the challenges posed by rapidly changing technology and equity of access [3], [11], [12], [13]; and especially, the lack of interoperability standards.

\section{INTEROPERABILITY STANDARDS AND LEARNING TECHNOLOGIES}

Interoperability is the ability of one product to interface or exchange data with another. Interoperability may convey clear benefits, including:

- Allowing consumers to more freely choose among competing products;

- Supplying a stable context for technical innovation; and

- Serving as a catalyst for mass-market adoption by assuring consumers that a new system will work properly with the ones they already have and that it can eventually be replaced with minimal disruption.

The traditional means to achieve interoperability is an engineering specification, such as those produced by the open and rigorous process in IEEE standards activities.

In terms of interoperability requirements for learning technology, the IEEE LTSC (Learning Technology Standard Committee) has the responsibility to address many interoperability related-problems such as descriptive resource metadata, specialised content formats, pedagogical models, administrative data, competency definition and learning performance criteria.

As learning technologies incorporate more intelligent features, they will generate and require significantly more data about learners, learning activities, and outcomes. Their commercial success will depend in part on their ability to create value by leveraging these data across multiple systems, jurisdictions, and stages of a life. Economically, and in terms of efficient progress of technology, it makes sense for learning systems to securely share their data rather than to hoard it, which is why standardised formats for data exchange are so important.

\section{THE IEEE ADBOOK FOR STEM EDUCATION}

As noted, interoperability standards help learning technologies integrate with existing infrastructure and processes. This means that innovations developed to meet the needs of a niche market - say one dominated by relatively low bandwidth cellular access, or one in which a culture demands different levels and types of privacy - can still be used in other markets as well. Tools originally 
created for broader (or wealthier) markets would be more easily tailored for use elsewhere. As real-world example of a project where standards, new technologies, and unique requirements from a developing country have converged, we examine the IEEE ADBook for STEM Education [14].

The IEEE ADBook project grew out of paper presented at the IEEE Global Humanitarian Technology Conference in 2011 that discussed a broadly applicable framework for building educational applications that combined field data collection and data visualization [15]. The requirements for the system presented in that paper came from the rice ecosystem management on the Indonesian island of Bali. In January 2013, the suggestions in the paper were incorporated in the IEEE's ADBook project. The goal of this one-year Research \& Development collaboration is to define and demonstrate an actionable data book consisting of a specialised eBook based on open standards that is tailored to support STEM education and supports learner accessibility and usage preferences. The requirements for the actionable data book are that it must be able to:

- Use camera and GPS data from a learner's mobile platform

- Use measurements from local lab equipment

- Exchange results of learning interactions with cloudbased LMSs, analytics engines, and other applications

- Retrieve content from cloud-based sources (e.g. content repositories)

- Store and retrieve student history and preferences in the cloud

Operationally, the project is hosted by Industry Connections, an IEEE Standards Association program that facilitates the early exploration of potential interoperability solutions [16]. Participation is free and open to interested parties. The IEEE ADBook project may continue past the initial year's charter, depending upon success.

Technologically, the project anticipates the global availability of a class of mobile devices comprising smart phones and connected tablets and explores the premise that those devices, in conjunction with a new content format, may provide the first truly global platform for connected learning. The format in question is EPUB3 [17], [18], a new eBook format defined by the International Digital Publishing Forum [19].

EBooks have emerged as a mass-market commercial success within the past few years. To date, eBooks have only replicated the static content of printed books in a digital medium, but EPUB 3 introduces interactivity to eBooks by embracing JavaScript and the HTML5 standard for web page content. These characteristics make EPUB3 an attractive foundation for a more fully-featured learning delivery platform. EPUB3 offers a complete solution for portable, interactive, connected content, and it is relatively simple to map the requirements for an interactive learning activity onto baseline EPUB3 capabilities. Since EPUB3 is a generalpurpose technology with broad appeal outside of the education industry, it is more likely than education-specific standards to be widely adopted, supported, and have a multidecade life span.

Although most of the technology used by the IEEE ADBook project was developed for commercial purposes in the developed world, its application to learning was originally inspired by the desire to enable students in remote locations to collect field data and share their data and culture with other students in the United States. The first use case to which it will be applied is the construction of an enhanced, interactive guidebook for the new UNESCO World Heritage site on Bali [20], [21], [22].

The UNESCO site covers a significant geographical area encompassing 21 communities engaged in rice production and following traditional spiritual practices. This has resulted in an enormous challenge: How does one design an interactive guidebook that promotes the conservation and preservation of the site while meeting the needs of the people who live there, the international team developing and maintaining the site, and tourists from all over the world with varying degrees of cultural sensitivity? The IEEE ADBook project aims to help meet these requirements by developing onsite learning activities and guides that adapt to the local geography and culture as well as to those of the user's culture. The project will also support remote connectivity, allowing students to vicariously experience the site from anywhere on the planet.

The UNESCO site is just an example of the affordances of the IEEE ADBook. As noted above, the project is intended to support generic STEM education as well as learner accessibility and usage preferences. In this respect, the challenge for the IEEE ADBook is to be regarded by the learning and teaching community as a improved platform that supports modern approaches to meaningful and transformative learning. In the next section we discuss the values of the IEEE ADBook in the light of contemporary learning theoretical frameworks.

\section{THE IEEE ADBOOK VALUE AS A PLATFORM FOR GLOBAL CONNECTED LEARNING}

So far we have discussed the basic functionality of the IEEE ADBook as a general purpose learning delivery platform for global connected learning. However, it is important to discuss the value of the platform in light of learning principles and theories.

According to Oblinger [23], the rapidly changing technology may have a serendipitous impact on learning. Today's learners have no fear of technology and, as it is an integral part of their lives, they are happy to use technology for transformative learning purposes anywhere, anytime. In this regard, the IEEE ADBook has been conceived in a time when new products built on emerging technologies such as tablets, mobile devices, cloud-based services, and eBooks 
have generated widespread discussion about disruptive change in education at all levels.

However, for learning to occur there is a need to rethink the effective use of these emerging technologies to facilitate active, social, and experiential learning. One aspect that comes to the picture is the particular affordances and constraints of technology in supporting communicative and adaptive media. Laurillard [7] argues that any one technology can be analysed and understood to afford some types of usages and behaviours while constraining others. Her analytical framework, which identifies the affordances of both communicative media and adaptive media, is useful in terms of the rationale behind the IEEE ADBook. In fact, the IEEE ADBook taps into these affordances to support the discursive, adaptive, interactive, and reflective process characteristic of a learning activity.

Another relevant aspect of the IEEE ADBook is its support for learners' preferences and the way they approach learning. According to Kolb [24], learning is a process where the learner constructs knowledge through his /her experiences with the environment. He sees knowledge as the result of combining the way individuals grasp and transform their experiences [24]. According to this experiential learning theory, there are two dialectically related modes of grasping experience: Concrete Experience (CE) and Abstract Conceptualisation (AC). Similarly, there are two dialectically related modes of transforming experience: Reflective Observation (RO) and Active Experimentation (AE).

For example, when a learner is exposed for the first time to a concrete experience (CE), there is an initial stimulus for the reflective observation (RO) of the new experience, which in turn gives rise to a thinking process characterised by abstraction and conceptualisation (AC) to assimilate the new experience. Once the new experience is assimilated the learner is prepared to act upon and transforming it into something different through active experimentation (AE). This learning cycle repeats in the construction of new knowledge and varies depending on the personality and experiences of the learner [24]. In other words, there is a preferred way of choosing amongst the four abovementioned modes of learning shaped by individual's previous experiences, learning behaviours, prior learning and the learning environment. From the perspective of STEM education, and in terms of Kolb's modes of learning, STEM learners are individuals with a converging style of learning with abstraction, conceptualisation, and active experimentation as the main dominant learning abilities. As noted above, the IEEE ADBook addresses these STEM requirements by supporting learner accessibility and usage preferences.

One of the most distinguishing and valuable features of the IEEE ADBook is its capacity to enable global connected learning. This is consistent with Siemens' connectivism theory of learning. According to Siemens [25], traditional learning theories like behaviourism, cognitivism, and constructivism were developed in a time when technology was not seen as fundamental for learning. Today, influenced by ubiquitous technology, we live, communicate, and learn in a rapidly changing world. Accordingly, there is a need for more appropriate learning theories and principles to explain how we acquire knowledge. In connectivism, Siemens explains learning as a 'process that occurs within nebulous environments of shifting core elements - not entirely under the control of the individual' [25]. He defines learning as 'actionable knowledge'; that explicit knowledge that can only be acquired through the established connections amongst interested parties. In this regard, the IEEE ADBook is envisaged to be actionable in supporting these connections for interactive and dialogical conversations in STEM education.

\section{Potential Case Studies}

As mentioned, the first application for the IEEE ADBook will be the construction of an interactive guidebook for the new UNESCO World Heritage site on Bali. In terms of STEM education, the IEEE ADBook is expected to tap into newly emerging product categories. Some will be engendered by societal requirements and others by advances in educational technology.

For example, students and teachers are increasingly connected with multiple institutions at the same time [26], and many of the more innovative learning technologies are typically used outside standard classroom practice. This may require tracking of rosters, assignments, progress, and grades across multiple institutions and multiple online learning systems. Students' history and preferences will be maintained in an external 'learner model' [27], [28], [29] [ or e-portfolio which can be updated and queried by multiple adaptive learning systems. The natural evolution of the eportfolio will be a personal learning record store that:

- is securely controlled by the learner;

- is portable as the learner works with multiple schools, teachers, tutors, and publishers over the years; and

- contains the learner's preferences and his validated and certified formal and informal learning history.

This evolution of the learner's history records would parallel the recent evolution of Electronic Health Records and, if implemented on a global scale, would spawn a plethora of products, ranging from tools to manage learning records to learning applications that take advantage of them to deliver more personalised, culturally relevant, and educationally effective learning experiences.

Similarly, advances in cognitive science, computer science, and information technology are also creating both requirements and affordances for new product categories. Just as the underlying technological components of expert systems have now found their way into hundreds of products from rice cookers to mobile phones, we anticipate that the AI components of today's intelligent tutoring systems will work their way into a wide range of learning products. The same is true for automated language understanding [30], automated grading [31], affect detection [32], [33], gesture and sketch 
recognition [34], [35], [36], and forms of social media that enable students to collaborate with each other and with adults (e.g. "granny tutors") [37].

\section{CONCLUSION}

In this paper, and in the spirit of the global humanitarian community, we propose the IEEE ADBook has the capacity to become the first truly global framework for connected learning supporting inclusive education in developing countries. This model of learning is timely both because of the rapid adoption of emerging technologies in the developing world and the wider range of new technical capabilities to support transformative and authentic learning. Central to the model is its flexible configuration that makes it scalable, cost-effective, sustainable, and easy to implement in disparate systems. The model is grounded in learning principles and theory that highlight the impact of technology in contemporary teaching and learning at all levels.

If your vision for education involved producing online digital content for use in multiple institutions or jurisdictions - content that must communicate with other systems - please put the IEEE ADB project on your radar. Interested parties are welcome to participate in the early exploratory work at the IEEE ADBook project or to monitor our progress at http://www.ieee-adb.org/

\section{REFERENCES}

[1] United Nations, "The Millennium Development Goals Report," United Nations, New York, 2012.

[2] G. Trentin and S. Wheeler, “A Critical review of blended learning in the UK: What Future for the LMS?," in in Effective Blended Learning Practices: Evidence-Based Perspectives in ICT- Facilitated Education, E. Stacey and P. Gerbic, Eds. Hershey, PA: IGI Global Press, 2009.

[3] L. Wise and Quealy, “LMS Governance Project Report,” 2006. [Online].

Available: http://www.infodiv.unimelb.edu.au/telars/talmet/melbmonash/media/ LMSGovernanceFinalReport.pdf.

[4] ITU, "The World in 2010: ICT Facts and Figures," 2010

[5] H. Coates, R. James, and G. Baldwin, "A critical examination of the effects of learning management systems on university teaching and learning,” Tert. Educ. Manag., vol. 11, no. 1, pp. 19-36, Mar. 2005

[6] D. R. Garrison and H. Kanuka, "Blended learning: Uncovering its transformative potential in higher education," Internet High. Educ., vol. 7, no. 2, pp. 95-105, 2004.

[7] D. Laurillard, Rethinking university teaching: a conversational framework for the effective use of learning technologies. London; New York: RoutledgeFalmer, 2002.

[8] C. Keller and L. Cernerud, "Student's perceptions of E-learning in education,” Learn. Media Technol., vol. 27, no. 1, pp. 55-67, 2002.

[9] M. Oliver and K. Trigwell, “Can 'Blended Learning’ be redeemed?,” E-Learn., vol. 2, no. 1, pp. 17-26, 2005.

[10] J. M. O’Toole and D. J. Absalom, "The impact of blended learning on student outcomes: Is there room on the horse for two?," J. Educ. Media, vol. 28, no. 2-3, pp. 179-189, 2003.

[11] J. D. Bain and C. McNaught, "How academics use technology in teaching and learning: Understanding the relationship between beliefs and practice,” J. Comput. Assist. Learn., vol. 22, no. 2, pp. 99-113, 2006.

[12] C. Raby and H. Meunier, "Factors influencing ICT integration according to the teacher's level of pedagogical integration," in Proceedings of Society for Information Technology \& Teacher Education International Conference 2011, Chesapeake, VA, 2011, pp. 2667-2673.

[13] J. Steel and A. Hudson, "Educational Technology in Learning and Teaching: The Perceptions and Experiences of Teaching Staff," Innov. Educ. Teach. Int., vol. 38, no. 2, pp. 103-111, 2001.

[14] IEEE ADB Project, "Public Home Page: The IEEE Actionable Data Book for S.T.E.M. Education,” 2013. [Online]. Available: http://www.ieee-adb.org/.

[15] [15] T. Richards and A. Barr, "Catalyzing Connected Learning through Standards,” in Global Humanitarian Technology Conference (GHTC), 2011 IEEE, pp. 503-505.

[16] T. Richards, "IEEE Actionable Data Book for STEM Education: Industry Connections Activity Initiation Document (ICAID),” 2012. [Online]. Available: http://standards.ieee.org/about/sasb/iccom/IC12006-. [Accessed: 29-May-2013].

[17] M. Garrish, What is EPUB 3? O’Reilly Media, 2011.

[18] IDPF, “EPUB 3.” [Online]. Available: http://idpf.org/epub/30. [Accessed: 29-May-2013].

[19] IDPF, “IDPF Home Page.” [Online]. Available: http://idpf.org/. [Accessed: 29-May-2013].

[20] J. S. Lansing and J. N. Watson, "Guide to Bali’s UNESCO World Heritage, Tri Hita Karana: Cultural Landscape of Subaks and Water Temples," 2012.

[21] UNESCO, "Cultural Landscape of Bali Province: the Subak System as a Manifestation of the Tri Hita Karana Philosophy," 2012 [Online]. Available: http://whc.unesco.org/en/list/1194/. [Accessed: 29-May-2013]

[22] J. S. Lansing and J. N. Watson, Water temples forever. 2012

[23] D. Oblinger, Learning spaces. EDUCAUSE, 2006.

[24] D. A. Kolb, "David A. Kolb’s Experiential Learning Theory and the Learning Styles Inventory,” 2005. [Online]. Available: http://www.icels-educators-for-

learning.ca/index.php?option $=$ com content \&view=article\&id=50\&It emid=65. [Accessed: 29-May-2013].

[25] G. Siemens, "elearnspace. Connectivism: A Learning Theory for the Digital Age.” [Online]. Available: http://www.elearnspace.org/Articles/connectivism.htm. [Accessed: 29-May-2013]

[26] P. Newbaker, "No Straight Path to College Graduation,” National Student Clearinghouse, 2012.

[27] R. Sottilare, H. Holden, A. C. Graesser, and X. Hu, Design Recommendations for Adaptive Intelligent Tutoring Systems: Learner Modeling (Vol. 1). Army Research Lab, 2013.

[28] B. P. Woolf, Building intelligent interactive tutors: Student-centered strategies for revolutionizing e-learning. Burlington, MA: Morgan Kaufmann, 2009.

[29] P. J. Durlach and J. M. Ray, "Designing adaptive instructional environments: Insights from empirical evidence,” Army Research Institute, Arlington, VA, Oct. 2011

[30] R. Robson and F. Ray, “Applying Semantic Analysis to Training, Education, and Immersive Learning," presented at the The Interservice/Industry Training, Simulation \& Education, 2012.

[31] S. Valenti, F. Neri, and A. Cucchiarelli, "An overview of current research on automated essay grading,” J. Inf. Technol. Educ., vol. 2, pp. 319-330, 2003.

[32] M. Hussain, O. AlZoubi, R. A. Calvo, and S. K. D’Mello, “Affect detection from multichannel physiology during learning sessions with AutoTutor,” in Artificial Intelligence in Education, 2011, pp. 131138.

[33] [33] R. A. Calvo and S. D’Mello, "Affect detection: An interdisciplinary review of models, methods, and their applications," Affect. Comput. Ieee Trans., vol. 1, no. 1, pp. 18-37, 2010. 
[34] [34] D. Weinland, R. Ronfard, and E. Boyer, “A survey of visionbased methods for action representation, segmentation and recognition,” Comput. Vis. Image Underst., vol. 115, no. 2, pp. 224241, 2011.

[35] [35] S. Valentine, F. Vides, G. Lucchese, D. Turner, H. Kim, W. Li, J. Linsey, and T. Hammond, "Mechanix: A Sketch-Based Tutoring and Grading System for Free-Body Diagrams,” Ai Mag., vol. 34, no. 1, p. 55, 2012.
[36] [36] P. Yin, K. D. Forbus, J. Usher, B. Sageman, and B. Jee, "Sketch worksheets: A sketch-based educational software system," in Proceedings of the 22nd Innovative Applications of Artificial Intelligence Conference, Atlanta.

[37] [37] C. Doctorow, Deploying the British Granny Cloud to tutor poor Indian classrooms over Skype. 2011. 